Article

\title{
Sympatric Populations of the Anopheles gambiae Complex in Southwest Burkina Faso Evolve Multiple Diverse Resistance Mechanisms in Response to Intense Selection Pressure with Pyrethroids
}

\author{
Jessica Williams ${ }^{1} \mathbb{D}$, Victoria A. Ingham ${ }^{1,+} \mathbb{D}$, Marion Morris ${ }^{1}$, Kobié Hyacinthe Toé ${ }^{2,3} \mathbb{D}^{\mathbb{D}}$, Aristide S. Hien ${ }^{4} \mathbb{D}$, \\ John C. Morgan ${ }^{1}$, Roch K. Dabiré ${ }^{4}$ D, Wamdagogo Moussa Guelbéogo ${ }^{2}$, N’Falé Sagnon ${ }^{2}$ and Hilary Ranson ${ }^{1, *(D)}$
}

check for updates

Citation: Williams, J.; Ingham, V.A.; Morris, M.; Toé, K.H.; Hien, A.S.; Morgan, J.C.; Dabiré, R.K.; Guelbéogo, W.M.; Sagnon, N.; Ranson, H. Sympatric Populations of the Anopheles gambiae Complex in Southwest Burkina Faso Evolve Multiple Diverse Resistance Mechanisms in Response to Intense Selection Pressure with Pyrethroids. Insects 2022, 13, 247. https:// doi.org/10.3390/insects13030247

Academic Editor: Geoffrey M. Attardo

Received: 10 December 2021 Accepted: 21 February 2022 Published: 28 February 2022

Publisher's Note: MDPI stays neutral with regard to jurisdictional claims in published maps and institutional affiliations.

Copyright: (C) 2022 by the authors. Licensee MDPI, Basel, Switzerland. This article is an open access article distributed under the terms and conditions of the Creative Commons Attribution (CC BY) license (https:// creativecommons.org/licenses/by/ $4.0 /)$.
1 Vector Biology Department, Liverpool School of Tropical Medicine, Pembroke Place, Liverpool L3 5QA, UK; jessica.williams@lstmed.ac.uk (J.W.); victoria.ingham@uni-heidelberg.de (V.A.I.); marion.morris@lstmed.ac.uk (M.M.); john.morgan@lstmed.ac.uk (J.C.M.)

2 Centre National de Recherche et de Formation sur le Paludisme (CNRFP), Ouagadougou 01 BP 85, Burkina Faso; toe_kob@yahoo.fr (K.H.T.); guelbeogo.cnrfp@fasonet.bf (W.M.G.); n.fale.cnlp@fasonet.bf (N.S.)

3 Laboratory of Fundamental and Applied Entomology, Université Joseph KI-ZERBO, Ouagadougou 01 BP 85, Burkina Faso

4 Institut de Recherche en Sciences de la Santé (IRSS), Bobo-Dioulasso 01 BP 390, Burkina Faso; aristide.hien@yahoo.fr (A.S.H.); dabireroch@gmail.com (R.K.D.)

* Correspondence: Hilary.Ranson@lstmed.ac.uk

† Current address: Heidelberg University Hospital, Im Neuenheimer Feld 324, 69120 Heidelberg, Germany.

Simple Summary: Targeting mosquitoes with insecticides is one of the most effective methods to prevent malaria transmission. Although numbers of malaria cases have declined substantially this century, this pattern is not universal and Burkina Faso has one of the highest burdens of malaria; it is also a hotspot for the evolution of insecticide resistance in malaria vectors. We have established laboratory colonies from multiple species within the An. gambiae complex, the most efficient group of malaria vectors in the world, from larval collections in southwest Burkina Faso. Using bioassays with different insecticides widely used to control public health pests, we provide a profile of insecticide resistance in each of these colonies and, using molecular tools, reveal the genetic changes underpinning this resistance. We show that, whilst many resistance mechanisms are shared between species, there are some important differences which may affect resistance to current and future insecticide classes. The complexity, and diversity of resistance mechanisms highlights the importance of screening any potential new insecticide intended for use in malaria control against a wide range of populations. These stable laboratory colonies provide a valuable resource for insecticide discovery, and for further studies on the evolution and dispersal of insecticide resistance within and between species.

Abstract: Pyrethroid resistance in the Anopheles vectors of malaria is driving an urgent search for new insecticides that can be used in proven vector control tools such as insecticide treated nets (ITNs). Screening for potential new insecticides requires access to stable colonies of the predominant vector species that contain the major pyrethroid resistance mechanisms circulating in wild populations. Southwest Burkina Faso is an apparent hotspot for the emergence of pyrethroid resistance in species of the Anopheles gambiae complex. We established stable colonies from larval collections across this region and characterised the resistance phenotype and underpinning genetic mechanisms. Three additional colonies were successfully established (1 An. coluzzii, 1 An. gambiae and 1 An. arabiensis) to add to the $2 \mathrm{An}$. coluzzii colonies already established from this region; all 5 strains are highly resistant to pyrethroids. Synergism assays found that piperonyl butoxide (PBO) exposure was unable to fully restore susceptibility although exposure to a commercial ITN containing PBO resulted in $100 \%$ mortality. All colonies contained resistant alleles of the voltage gated sodium channel but with differing proportions of alternative resistant haplotypes. RNAseq data confirmed the role of 
P450s, with CYP6P3 and CYP6Z2 elevated in all 5 strains, and identified many other resistance mechanisms, some found across strains, others unique to a particular species. These strains represent an important resource for insecticide discovery and provide further insights into the complex genetic changes driving pyrethroid resistance.

Keywords: malaria vector; insecticide resistance; insecticide treated nets; cytochrome P450s; kdr; cuticular resistance

\section{Introduction}

Pyrethroid insecticides have played a key role in interrupting malaria transmission. All insecticide treated nets (ITNs) in use contain pyrethroids; they are the major active ingredient in insecticidal household aerosol sprays and coils and, prior to the advent of widespread resistance, they were the preferred chemistry for use in indoor residual spraying programmes [1]. Malaria vectors will also likely encounter pyrethroids in their aquatic habitats as this insecticide class is still widely used in agriculture, and mosquito breeding sites in rural areas frequently contain detectable levels of insecticides utilised to spray nearby crops $[2,3]$.

Resistance to pyrethroids was first detected in African malaria vectors in the 1970s [4] and is now widespread [5], prompting the search for new chemistries for use in vector control tools. Whether re-purposing chemistries used to control other pest species, or searching for new insecticide classes, the identification of suitable chemistries requires a robust screening pipeline that includes screening potential compounds against a range of mosquito populations resistant to current chemistries [6,7]. Whilst ultimately testing against natural wild populations will be required, the availability of stable laboratory colonies of the predominant vector species, containing the major resistance mechanisms circulating in the field can greatly accelerate the insecticide screening pipeline by identifying resistance liabilities at an early stage [8].

We have previously described the properties of several colonies of Anopheles mosquitoes that have been widely used in insecticide discovery programmes; these contain well characterised target site mutations and metabolic resistance conferred by elevated levels of specific pyrethroid metabolising cytochrome P450s [9]. However, recent studies on Anopheles gambiae s.l. mosquito populations from West Africa have identified additional, potent pyrethroid resistance mechanisms such as reduced penetration caused by cuticular thickening $[10,11]$, insecticide sequestration by pyrethroid binding proteins in the mosquito appendages and novel resistance associated haplotypes of the pyrethroid target site, the voltage gated sodium channel (VGSC) [12-14]. Several of these resistance mechanisms could potentially cause cross resistance to existing or new classes of insecticides; thus, we sought to establish new colonies of pyrethroid resistant An. gambiae s.l. from Burkina Faso, stabilise and quantify their pyrethroid resistance phenotypes and determine the underpinning mechanisms responsible for resistance.

An. gambiae is a species complex of at least nine morphologically identical species. Three of these (An. gambiae s.s, Anopeheles coluzzii and Anopheles arabiensis) are amongst the most important malaria vectors and are found in Burkina Faso [15]. Introgression of genes under selection pressure is not uncommon between members of the complex with several well documented cases of exchange of haplotypes containing point mutations in insecticide target sites $[16,17]$. The Southwest region of Burkina Faso is an important agricultural region of the country and also an area of stubbornly persistent malaria transmission, perhaps partially linked to the exceptionally high levels of pyrethroid resistance in the malaria vectors from this region $[18,19]$. We established three new colonies from larval collections in the Cascades and Southwest regions of Burkina Faso between 2015 and 2018, encompassing each of the three members of the An. gambiae complex found in the country. Phenotyping and molecular characterisation of these new colonies, the previously established Banfora 
M colony (Cascades region) and the VK72014 colony (neighbouring Hauts Basin region), revealed high levels of pyrethroid resistance with four colonies meeting the WHO definition of high intensity resistance and the fifth with moderate intensity. Genotyping and RNAseq identified resistance mechanisms in common between strains but also key differences that may have implications for susceptibility to alternative insecticide classes.

\section{Materials and Methods}

\subsection{Establishment of Strains}

Details of the strains used in this study are provided in Table 1. The origins of the susceptible strains Kisumu and Moz and the pyrethroid resistant Burkina Faso populations VK7 2014 and Banfora M have been described previously [9]. Larval collections from multiple villages in the Comoé Province, Cascades region of Burkina Faso in 2015 led to the establishment of two strains: Bakaridjan and Banfora. Briefly, larvae were reared to adults, allowed to mate and then females transferred to Eppendorf tubes to oviposit individually as described previously [20]. Females were killed by freezing after oviposition. Dried females, and egg papers were transported to the Liverpool School of Tropical Medicine. Species ID on the F0 female was performed [21] and egg batches from An. gambiae (s.s.) or An. coluzzii females were pooled to establish two separate colonies. The An. coluzzii colony was named 'Banfora' after the Banfora district as the colony was established from collections from several villages within this district (Tiefora, Pont Maurice, Sikane and Djomale; Figure 1). The An. gambiae s.s. strain was named 'Bakaridjan' as the majority of egg batches used to establish this strain were collected from this village. The An. coluzzii Tiefora strain and the An. arabiensis Gaoua-ara strains were established as above from larval collections performed in Tiefora Village Comoé Province, Banfora District and Gaoua District, Poni Province in 2018. The insecticide-susceptible colony N'Gousso originated from Cameroon [22].

\subsection{Mosquito Rearing}

Insectaries were maintained under standard conditions at $26 \pm 2{ }^{\circ} \mathrm{C}$ and $70 \%$ relative humidity $\pm 10 \%$ under L12:D12 h light:dark photoperiod. All stages of larvae were fed on ground fish food (TetraMin ${ }^{\circledR}$ tropical flakes, Tetra ${ }^{\circledR}$, Blacksburg, VA, USA) and adults were provided with $10 \%$ sucrose solution ad libitum.

\subsection{Selection and Resistance Profiling}

The five insecticide resistant strains were routinely selected every 3rd to 5th generation with $0.05 \%$ deltamethrin to preserve their resistant phenotype. Insecticide papers were purchased from the WHO facility at the University Sains Malaysia (USM), Penang, Malaysia and used a maximum of 6 times following the WHO procedure [24]. Selection was undertaken at the adult stage ( $2-5$ days old) using the WHO susceptibility bioassay [24]. Exposure times varied between strains to ensure at least 50\% survival (VK7 $20142 \mathrm{~h}$, Banfora $\mathrm{M}$ and Bakaridjan 2-3 h, Gaoua-ara 2-4 h and Tiefora 4-5 h). All adults from the generation to be selected were exposed, with results scored from at least 100 individuals. Following exposure, the mosquitoes were transferred to holding tubes and supplied with $10 \%$ sucrose solution and the initial knockdown effect was scored immediately post exposure. At $24 \mathrm{~h}$ post exposure, mortality rates were recorded. Bioassays and $24 \mathrm{~h}$ holding periods were conducted at $26 \pm 2{ }^{\circ} \mathrm{C}$ and $80 \pm 10 \% \mathrm{RH}$. 
Table 1. Summary of the Anopheles gambiae s.l. mosquito strains used in the study.

\begin{tabular}{|c|c|c|c|c|}
\hline Strain & Species & Origin & Source & $\begin{array}{l}\text { Year Colony } \\
\text { Established }\end{array}$ \\
\hline $\begin{array}{c}\text { Kisumu } \\
\text { (susceptible strain) }\end{array}$ & An. gambiae (s.s.) & Kenya & $\mathrm{MR} 4$ & 1975 \\
\hline $\begin{array}{c}\text { N'Gousso } \\
\text { (susceptible strain) }\end{array}$ & An. coluzzii & Cameroon & CRID & 2006 \\
\hline $\begin{array}{c}\text { Moz } \\
\text { (susceptible strain) }\end{array}$ & An. arabiensis & $\begin{array}{c}\text { Chokwe, Southern } \\
\text { Mozambique } \\
\left(24^{\circ} 33^{\prime} 37^{\prime \prime} \mathrm{S}, 33^{\circ} 1^{\prime} 20^{\prime \prime} \mathrm{E}\right)\end{array}$ & $\begin{array}{c}\text { Established in LSTM from field } \\
\text { collections performed by JCM } \\
\text { with assistance from National } \\
\text { Institute of Health, } \\
\text { Mozambique [23] }\end{array}$ & 2009 \\
\hline VK7 2014 & An. coluzzii & $\begin{array}{c}\text { Houet Province, Burkina Faso } \\
\text { Valley de Kou } 7 \\
\left(11^{\circ} 24^{\prime} 29^{\prime \prime} \mathrm{N}, 4^{\circ} 24^{\prime} 37^{\prime \prime} \mathrm{W}\right)\end{array}$ & $\begin{array}{l}\text { Established from larval } \\
\text { collections performed by } \\
\text { LSTM (JCM) and } \\
\text { CNRFP (KHT) }\end{array}$ & 2015 \\
\hline Banfora M & An. coluzzii & $\begin{array}{c}\text { Comoé Province Burkina Faso } \\
\text { Banfora district (Tiefora, Pont } \\
\text { Maurice, Sikane and Djomale } \\
\left(10^{\circ} 38^{\prime} 0^{\prime \prime} \mathrm{N}, 4^{\circ} 33^{\prime} 0^{\prime \prime} \mathrm{W}\right) \text { and } \\
\text { Bakaridjan }\left(10^{\circ} 24^{\prime} 26.34^{\prime \prime} \mathrm{N},\right. \\
\left.\left.4^{\circ} 33^{\prime} 44.78^{\prime \prime} \mathrm{W}\right) \text { villages }\right)\end{array}$ & $\begin{array}{l}\text { Established from larval } \\
\text { collections performed by } \\
\text { LSTM (JCM) and } \\
\text { CNRFP (KHT) }\end{array}$ & 2015 \\
\hline Bakaridjan & An. gambiae (s.s) & $\begin{array}{c}\text { Comoé Province Burkina Faso } \\
\text { Banfora district (Tiefora, Pont } \\
\text { Maurice, Sikane and Djomale } \\
\left(10^{\circ} 38^{\prime} 0^{\prime \prime} \mathrm{N}, 4^{\circ} 33^{\prime} 0^{\prime \prime} \mathrm{W}\right) \text { and } \\
\text { Bakaridjan }\left(10^{\circ} 24^{\prime} 26.34^{\prime \prime} \mathrm{N},\right. \\
\left.\left.4^{\circ} 33^{\prime} 44.78^{\prime \prime} \mathrm{W}\right) \text { villages }\right)\end{array}$ & $\begin{array}{l}\text { Established from larval } \\
\text { collections performed by } \\
\text { LSTM (JCM) and } \\
\text { CNRFP (KHT) }\end{array}$ & 2015 \\
\hline Tiefora & An. coluzzii & $\begin{array}{l}\text { Comoé Province, Burkina Faso } \\
\text { Banfora district } \\
\left(10^{\circ} 37.447^{\prime} \mathrm{N}, 4^{\circ} 33.201^{\prime} \mathrm{W}\right)\end{array}$ & $\begin{array}{l}\text { Established from larval } \\
\text { collections performed by } \\
\text { LSTM (JCM) and } \\
\text { CNRFP (KHT) }\end{array}$ & 2018 \\
\hline Gaoua-ara & An. arabiensis & $\begin{array}{c}\text { Poni Province Burkina Faso } \\
\text { Gaoua district } \\
\left(10.3231^{\circ} \mathrm{N}, 3.1679^{\circ} \mathrm{W}\right)\end{array}$ & $\begin{array}{l}\text { Established from larval } \\
\text { collections performed by } \\
\text { IRSS (ASH) }\end{array}$ & 2018 \\
\hline
\end{tabular}

Each strain was profiled annually against eight insecticides (except VK7 2014 which was profiled against six insecticides) representing the different insecticide classes currently used for mosquito control, to monitor the stability of their resistance phenotype; as described in [9] insecticides used were permethrin, deltamethrin, alpha-cypermethrin, DDT, dieldrin, bendiocarb, propoxur and fenitrothion. Results for VK7 2014 and Banfora M have been reported previously [9], but are included here for comparative purposes.

The intensity of resistance was evaluated in the different strains using papers treated with $5 \times$ and $10 \times$ the diagnostic dose of permethrin following the WHO procedure [24]. 


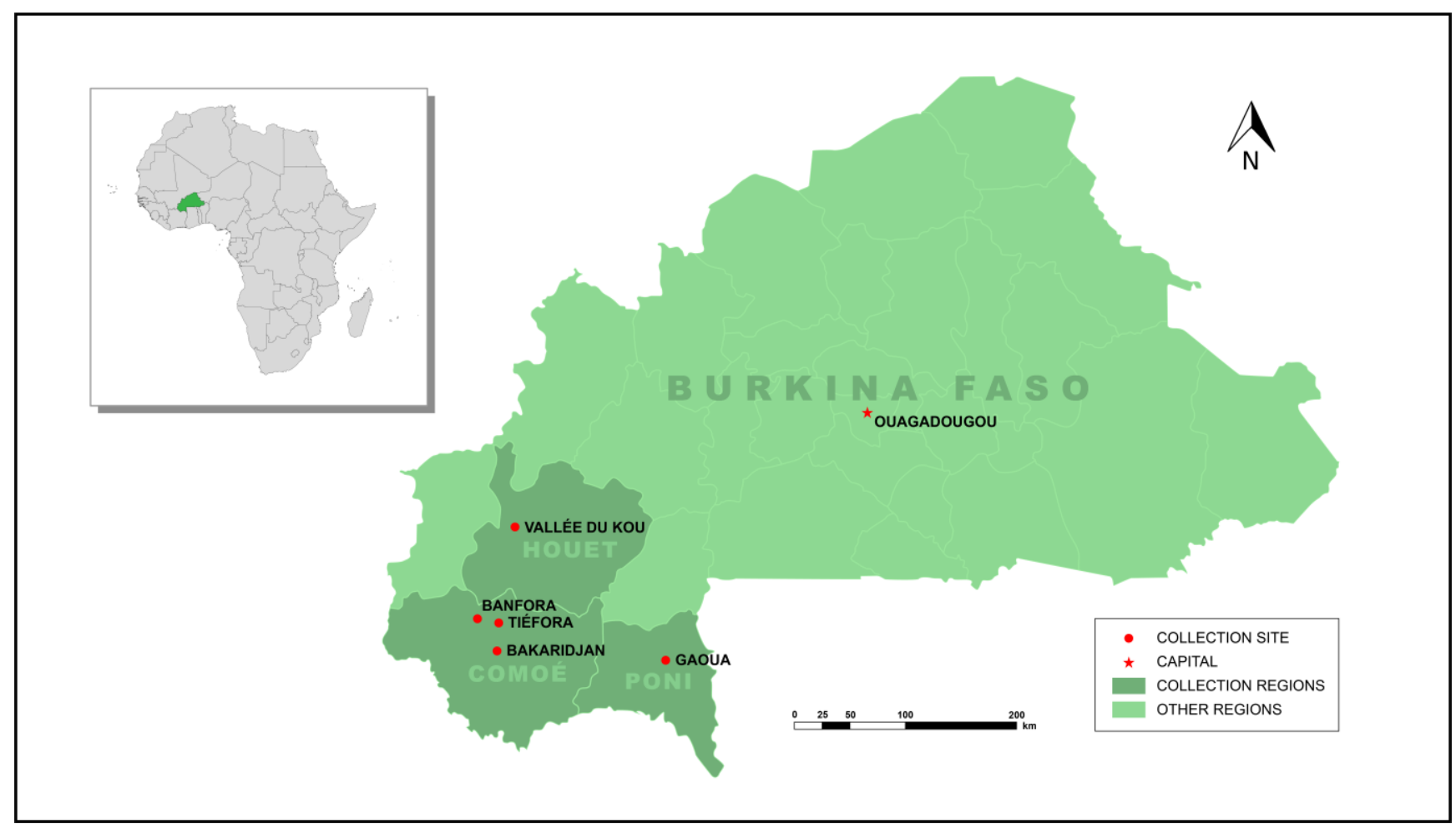

Figure 1. Map of Burkina Faso showing mosquito collection sites.

\subsection{Synergist Bioassays}

The impact of the synergist piperonyl butoxide (PBO) on pyrethroid induced mortality in each of the resistant strains was assessed in two separate experiments. Firstly, 2-5 day old female mosquitoes were pre-exposed to $\mathrm{PBO}$ papers impregnated with $\mathrm{PBO}(4 \%)$ followed by $1,2,3$ or $4 \mathrm{~h}$ exposures to papers impregnated with permethrin $(0.75 \%)$ according to the WHO protocol [24].

In the second experiment, mortality rates following sequential PBO then pyrethroid exposure were compared with simultaneous exposure to insecticide and synergist. Adult females from three strains were exposed to either (1) a pyrethroid only 1-h exposure; (2) a 1-h PBO pre-exposure followed by a 1-h pyrethroid exposure, or (3) a 1-h combination exposure (with $\mathrm{PBO}$ and either pyrethroid on the same paper). These experiments were performed separately using $0.75 \%$ permethrin papers and $0.05 \%$ deltamethrin papers.

In both experiments, solvent only paper (no AI) and a PBO control, where a 1-h PBO exposure was followed by 1-h blank exposure were included. Differences in mortality with and without PBO exposure were analysed for significance using Fisher's exact test.

\subsection{Cone Bioassays}

Mosquitoes were exposed to PermaNet ${ }^{\circledR} 3.0$ LN (Vestergaard Frandsen SA, Denmark) a LLIN consisting of a top panel made of monofilament polyethylene (100 denier) fabric incorporating deltamethrin at $4 \mathrm{~g} / \mathrm{kg}$ (approx. $180 \mathrm{mg} / \mathrm{m}^{2}$ ) and piperonyl butoxide at $25 \mathrm{~g} / \mathrm{kg}$ (approx. $1.1 \mathrm{~g} / \mathrm{m}^{2}$ ), plus side panels made of multifilament polyester (75 denier) fabric with a strengthened border treated with deltamethrin at $2.8 \mathrm{~g} / \mathrm{kg}$ (approx. $118 \mathrm{mg} / \mathrm{m}^{2}$ ) in WHO cone bioassays [25]. Following net airing of 2 weeks, pieces of netting $(25 \mathrm{~cm} \times 25 \mathrm{~cm})$ were cut from the roof and side of the PermaNet 3.0 and cohorts of approximately 50 mosquitoes of each strain were exposed using the WHO standard protocol. Controls were exposed to insecticide free net in two replicates, each with 5 mosquitoes, one just before and one just after the treated exposures. Following exposure, the mosquitoes were aspirated into paper cups and supplied with $10 \%$ sucrose solution, and the initial knockdown effect was scored at $1 \mathrm{~h}$ and mortality was scored at $24 \mathrm{~h}$ post exposure. 


\subsection{Target Site Mutation Genotyping}

Genomic DNA was collected within the first 5 months of colonisation of each strain and every subsequent 6-12 months thereafter. The DNA was extracted from 48 non-bloodfed females using a Qiagen blood and tissue DNA extraction kit (Qiagen, Germantown, MD, USA). Species ID was identified using the SINE PCR protocol [21].

Each strain was genotyped to identify the frequency of known target site resistance alleles (alleles 995F, 995S and 1570Y in the VGSC, the ace-1119S allele and the RDL alleles 296G and 296S) using Taqman ${ }^{\mathrm{TM}}$ assays [26-29]. The allelic variant 114T of the glutathione transferase GSTe2 gene was also genotyped as previously [30].

\subsection{RNAseq Transcriptomic Analysis}

RNA was extracted from pools of 5, 3-5 day old presumed-mated adult females, snap frozen in the $-80{ }^{\circ} \mathrm{C}$ at 10 am, using a PicoPure kit (Applied Biosystems Thermo Fisher, Waltham, MA, USA, after homogenisation with a motorised pestle. Quality and quantity of the RNA was analysed using an Agilent TapeStation (Santa Clara, CA, USA) and Nanodrop (Thermo Fisher) respectively, and three (Moz, Gaoua-ara, N'Gousso, Tiefora) or four (Banfora, VK72014, Kisumu, Bakaridjan) replicates from each strain sent for sequencing at Centre for Genomics, Liverpool, UK (RNA extractions for Banfora were performed as part of a separate study [31] but using the same methodology).

The resulting data was run through appropriate $\mathrm{QC}$ using Fast $\mathrm{QC}$ and aligned to the latest Anopheles gambiae s.l. genome assembly PEST4 using Hisat2 with default parameters. The resulting bam file was sorted using samtools and the number of reads aligned to each gene extracted using featureCounts. Over $70 \%$ read assignment was seen for each replicate of each population with the majority showing $>85 \%$. Data from the An. gambiae s.s and An. coluzzii resistant populations were compared to the two susceptible populations (Kisumu and N'Gousso) using limma. First, a model matrix was defined to account for the populations and then contrasts were made to compare the resistant An. gambiae and An. coluzzii to both susceptible populations through the function makeContrasts using resistant- $\left(\mathrm{N}^{\prime}\right.$ Gousso + Kisumu $) / 2$. Counts were then transformed to $\log 2$ counts per million reads (CPM), residuals calculated, and a smoothed curve fitted using the voom function which utilises normalisation factors calculated using calcNormFactors. $1 \mathrm{mFit}$ was used to fit a linear model for each gene and eBayes used to smooth the standard errors. The function topTable was then used to retrieve results and written out to file; significance was taken as adjusted $p$ value $\leq 0.05$. In the case of the single An. arabiensis population, the contrast matrix was simply a resistant vs. susceptible design. In each instance the filterByExpr function from the EdgeR package was used to remove genes with low read number. Enrichment analysis was performed using the built-in GO term enrichment analysis on VectorBase with a Benjamini significance cut-off of $\leq 0.05$. Revigo was then used to remove redundant GO terms allowing more appropriate visualisations; default parameters were used with a 0.5 selection. A custom table was also used with hypergeometric tests with fdr cut-off of $\leq 0.05$ to integrate KEGG, Reactome and a priori genes of interest into the enrichment analysis (https://github.com/VictoriaIngham/BurkinsStrains) (accessed on 9 December 2021). All RNAseq data is deposited in SRA under accession PRJNA780362 and PRJNA750256.

\subsection{Metabolic Resistance-Detox Gene Expression Levels}

One to four $\mu \mathrm{g}$ of RNA, extracted from three pools of 5, 3-5-day-old female as described above, was reverse transcribed using Oligo dT (Invitrogen, Warrington, UK) and Superscript III (Invitrogen). The resulting cDNA was diluted to $4 \mathrm{ng} / \mu \mathrm{L}$ and used as a template in the subsequent PCR reactions. Primers and probes as described by Maviridis et al. [32] were ordered from Integrated DNA Technologies (Leuven, Belgium), with Cy5 replacing Atto647N. Primers and probes were diluted to $10 \mu \mathrm{M}$ for use in a $10 \mu \mathrm{L}$ final reaction. Four multiplex reactions were carried out on each cDNA set in technical triplicate, as follows: (i) CYP6P4, CYP6Z1 and RPS7; (ii) CYP4G16 and CYP9K1; (iii) CYP6M2 and CYP6P1; 
(iv) CYP6P3 and GSTE2. PrimeTime Gene Expression Master Mix (Integrated DNA Technologies) was used to set up each reaction following the manufacturer's instructions. Each reaction was carried out on a MxPro 3005P qPCR System (Agilent) with the following thermocycling conditions: $3 \mathrm{~min}$ at $95^{\circ} \mathrm{C}$ followed by 40 cycles of $15 \mathrm{~s}$ at $95{ }^{\circ} \mathrm{C}$; $1 \mathrm{~min}$ at $60{ }^{\circ} \mathrm{C}$. Cycle threshold (Cq) values were exported and analysed using the $\Delta \Delta \mathrm{ct}$ methodology [33], using RPS7 as an endogenous control. Gaoua-ara were normalised against the susceptible Moz strain of An. arabiensis, and Bakaridjan, Banfora M, Tiefora and VK7 2014 were compared to both N'Gousso and Kisumu. A homogeneity of variance test was used to determine if data were normally distributed. $\Delta$ ct values were transformed to normalise (where applicable) and an ANOVA test, followed by Dunnett's test was performed. Where transformations did not normalise the data, a Dunn test was performed.

\section{Results}

\subsection{Discriminating Dose Assays}

Bakaridjan, Gaoua-ara, Banfora M, Tiefora and VK7 2014 are all resistant to pyrethroids and DDT according to WHO definitions [24] (Figure 2). Gaoua-ara and Tiefora are also resistant to the organochlorine dieldrin. Bakaridjan, Gaoua-ara and Tiefora are resistant to the carbamates propoxur and bendiocarb with Banfora $\mathrm{M}$ resistant to bendiocarb only. None of the five strains are resistant to the organophosphate fenitrothion. Kisumu and Moz are susceptible to all the insecticides tested and results have been reported previously [9]. N'Gousso showed less than $90 \%$ mortality after exposure to propoxur (87\%), DDT (61\%) and dieldrin (39\%) but was susceptible to other insecticides tested.

The results of profiling the five resistant strains against 5 and $10 \times$ diagnostic dose (DD) of permethrin are shown in Figure 3. All 5 strains survived exposure to $5 \times$ DD (mortality ranged from $14 \%$ to $71 \%$ ). Four of the strains also showed less than $90 \%$ mortality after exposure to $10 \times$ permethrin papers (and would be described by WHO as having high intensity resistance) whereas Gaoua-ara with $55 \%$ mortality with $5 \times$ papers, $98 \%$ mortality with $10 \times$ is defined by $\mathrm{WHO}$ as moderate to high intensity resistance.

\subsection{Impact of PBO on Pyrethroid Mortality}

All strains showed significant synergism when pre-exposed to PBO followed by a 4-h exposure to permethrin but synergism was not consistently observed with shorter pyrethroid exposures and PBO pre-exposure did not fully restore susceptibility to permethrin in any of the strains (Figure 4; full mortality results and synergism ratios are available in Supplementary Table S1). The highest synergist ratios were seen for Banfora where significant synergism was observed at all permethrin exposures greater than $2 \mathrm{~h}$ and PBO:permethrin synergism ratios ranged from 7:1 (2 h) to 54:1 (3 h). Negative controls (both control papers only and PBO followed by control papers) gave $<4 \%$ mortality in all assays.

In a separate set of experiments the effect of sequential versus simultaneous exposure to PBO and pyrethroids was compared (Supplementary Figure S1) with pyrethroid exposure duration constant at one hour. PBO did not synergise permethrin in these experiments but the efficacy of deltamethrin was significantly improved in all three strains with both PBO exposure methods ( $p<0.0001$ in all cases). Simultaneous exposure to PBO and pyrethroids results in increased mortalities compared to $\mathrm{PBO}$ pre-exposure for all three strains but this was only significant $(p<0.05)$ in Bakaridjan for both insecticides and in Banfora with deltamethrin. Full mortality results and synergism ratios are available in additional Supplementary Table S2. 


\section{Bakaridijan}

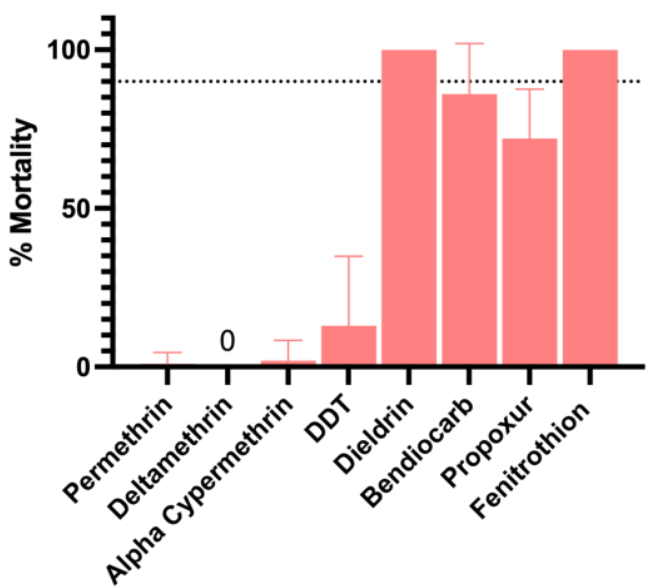

Banfora M

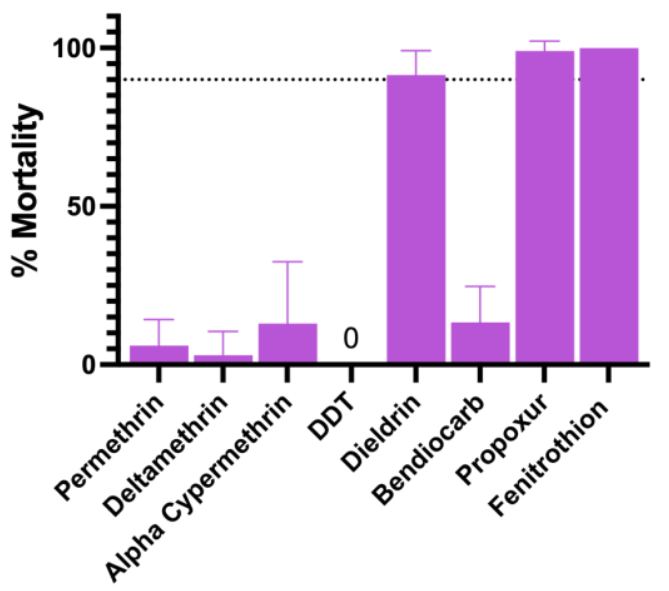

VK7 2014

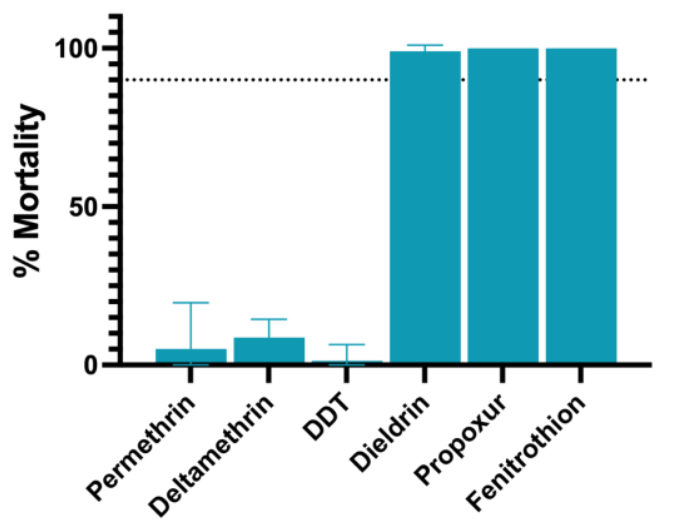

Gaoua-ara

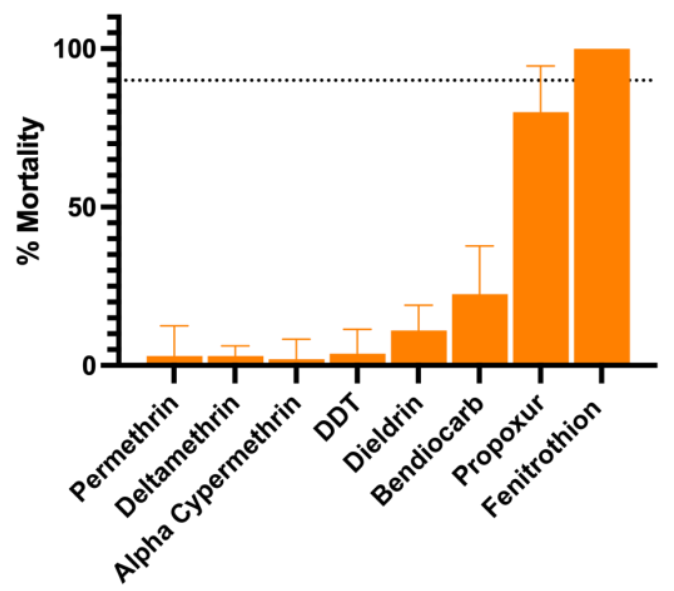

Tiefora

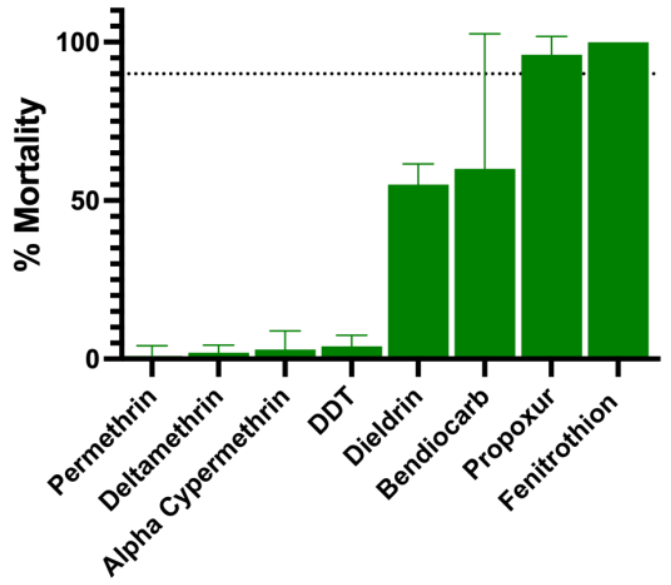

Figure 2. Mosquito mortality following exposure to insecticide papers in discriminating dose assays Mortality rates (\%) $24 \mathrm{~h}$ after exposure for 5 strains of Anopheles mosquito (results shown from assays performed in 2019). Minimum sample size $n=80$. Error bars represent $95 \%$ confidence intervals. Dotted line represents the WHO $90 \%$ mortality resistance threshold. 


\section{Permethrin Resistance Intensity}

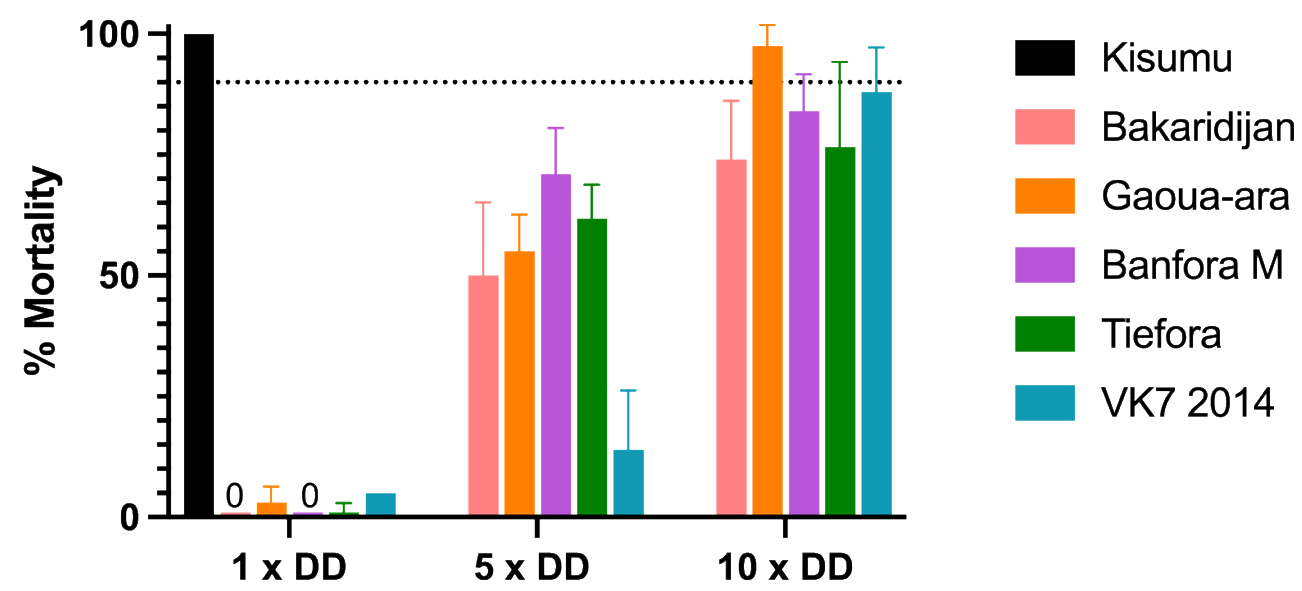

Figure 3. Mosquito mortality following exposure to permethrin papers in WHO resistance intensity assays. Mortality rates (\%) $24 \mathrm{~h}$ after exposure for 5 strains of Anopheles mosquito. Minimum sample size $n=80$. Error bars represent $95 \%$ confidence intervals. Dotted line represents the WHO $90 \%$ mortality resistance threshold. DD: Diagnostic dose.
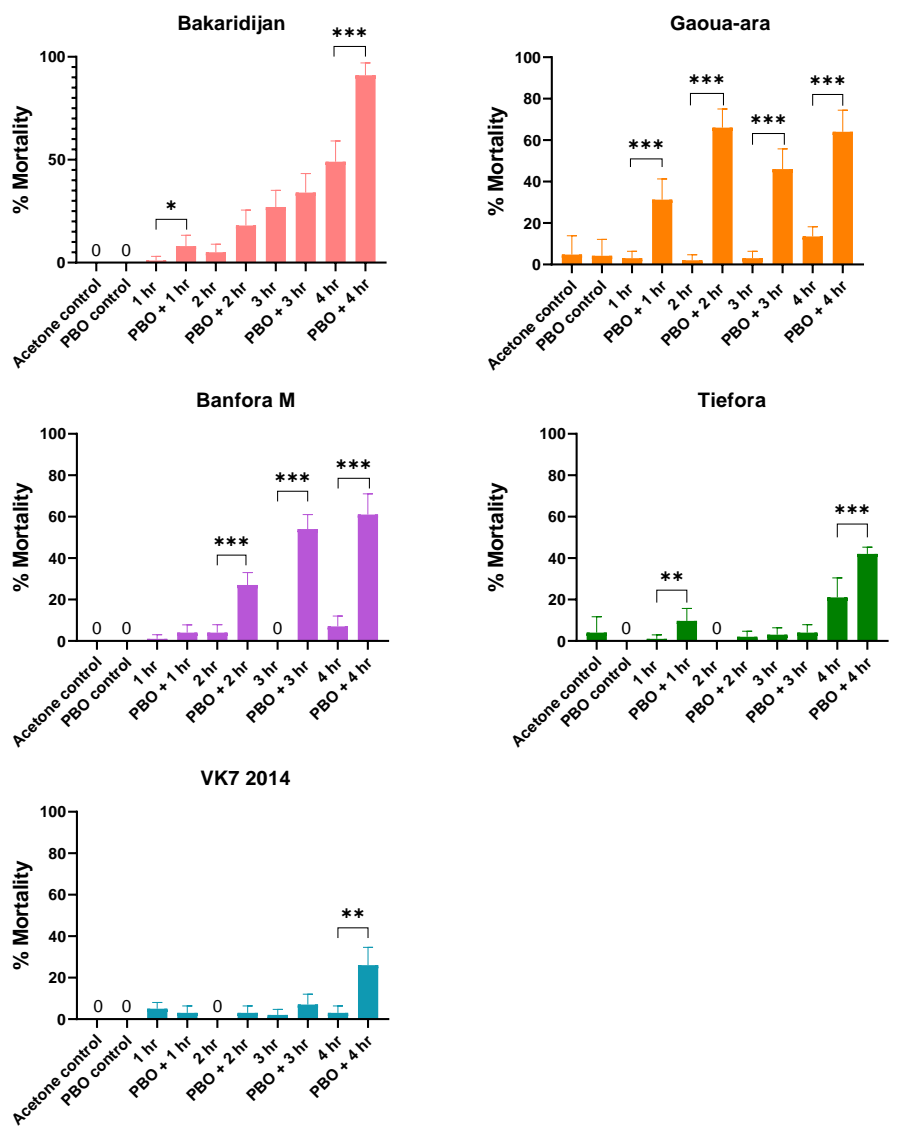

Figure 4. Mortality following exposure to permethrin with or without the synergist PBO. Mortality rates $\% 24 \mathrm{~h}$ after exposure. Minimum sample size $\mathrm{n}=80$. Error bars represent $95 \%$ confidence intervals. Statistical differences between permethrin only and $\mathrm{PBO}+$ permethrin for each paired combination indicated as ${ }^{*} p<0.05,{ }^{* *} p<0.001,{ }^{* * *} p<0.001$ Fisher's Exact test. 


\subsection{Cone Bioassays}

Exposure to the side of the PermaNet 3.0 net in a cone bioassay consistently resulted in $<10 \%$ mortality for all 5 strains but exposure to the roof (containing PBO) resulted in $>98 \%$ mortality (Figure 5).

\section{PN3 Cone Bioassay resistant strains only}

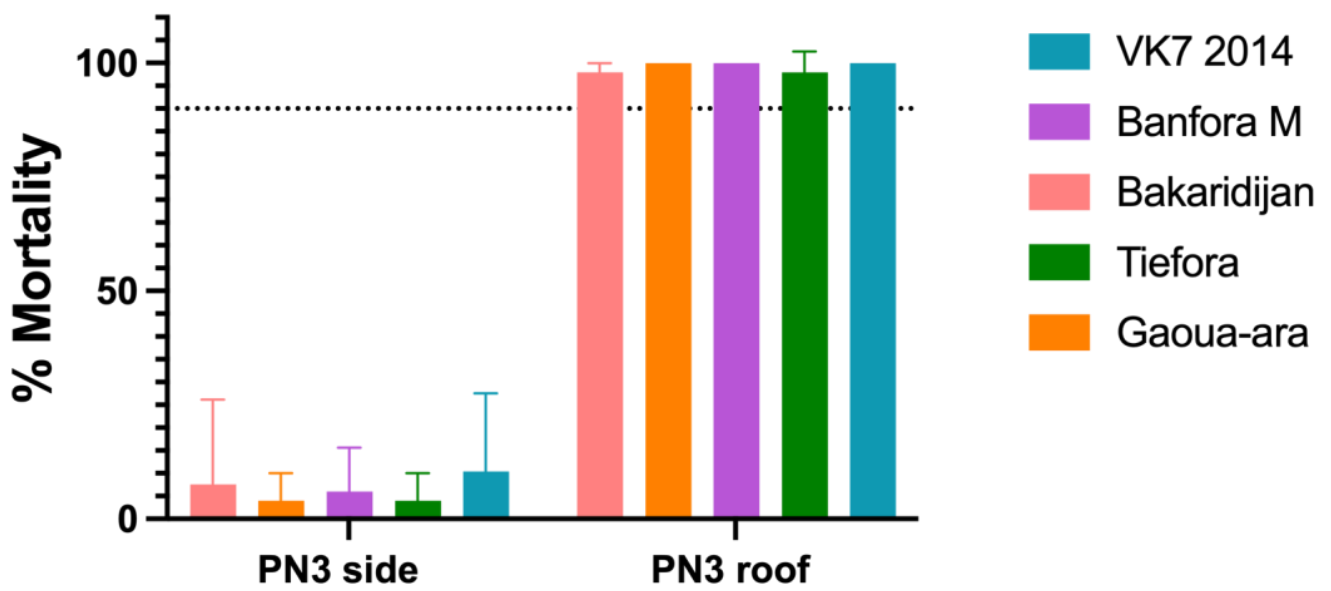

Figure 5. Mortality following exposure to Permanent 3.0 LLINs (PN3) in cone bioassays. Mortality rates $\% 24 \mathrm{~h}$ after exposure. Minimum sample size $\mathrm{n}=50$. Error bars represent $95 \%$ confidence intervals.

\subsection{Target Site Mutation Genotyping}

All the strains were screened for five target site mutations and one mutation in a detoxification gene (Figure 6). The 995F kdr allele was fixed in Bakaridjan and VK72014, but was present at quite low frequencies in Tiefora (allele frequency 0.06) and Banfora $\mathrm{M}$ (allele frequency 0.38). The An. arabiensis Gaoua-ara strain contained both 995F and 995S with allele frequencies of 0.49 and 0.45 , respectively. The 1570Y $\mathrm{kdr}$ allele was detected in Bakaridjan, VK7 2014, Banfora M and Tiefora with allele frequencies of 0.04, 0.35, 0.48 and 0.04 , respectively. The ace- 1 mutation was absent from all strains except a very low frequency in the Tiefora strain. The RDL 296S allele was detected in Gaoua-ara, Banfora M, VK7 2014, and Tiefora with allele frequencies of $0.65,0.22,0.03$ and 0.26 , respectively; only the wildtype form of A296 was found in the An. gambiae Bakaridjan strain. The GSTE2 114T detox gene modification was found in Banfora M, VK7 2014 and Tiefora with allele frequencies of $0.66,0.77$ and 0.46 , respectively.

\subsection{RNAseq Analysis}

RNAseq analysis was carried out on a minimum of three biological replicates from the five resistant strains and the three laboratory susceptible colonies, Kisumu, N'Goussu and Moz. The correlation matrix shows high degrees of similarity between the two An. arabiensis populations, Gaoua-ara and Moz but no clear segregation according to species for the An. gambiae and An. coluzzii strains (Supplementary Figure S2). Hence, for all further analysis of differential expression between resistant and susceptible strains, Gaoua-ara was compared to Moz alone whereas the three An. coluzzii (Tiefora, VK72014, Banfora) and one An. gambiae s.s.(Bakaridjan) resistant strains were compared to the average values from the two susceptible strains of An. coluzzii (N'Gousso) and An. gambiae (Kisumu). 


\section{L995F/S genotype frequencies}

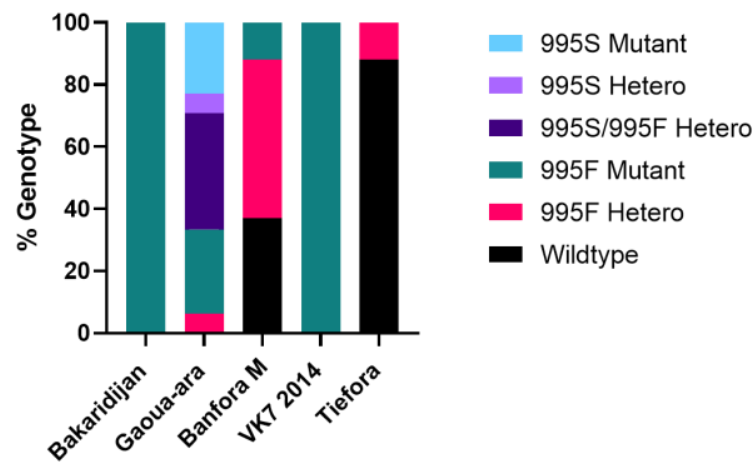

Ace-1 G119S genotype frequencies

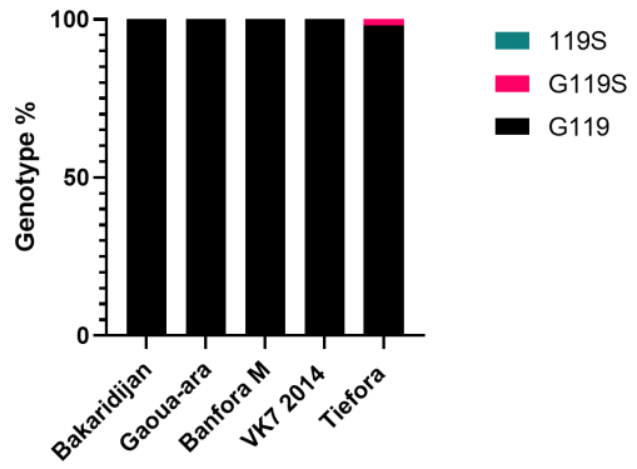

\section{N1750Y genotype frequencies}

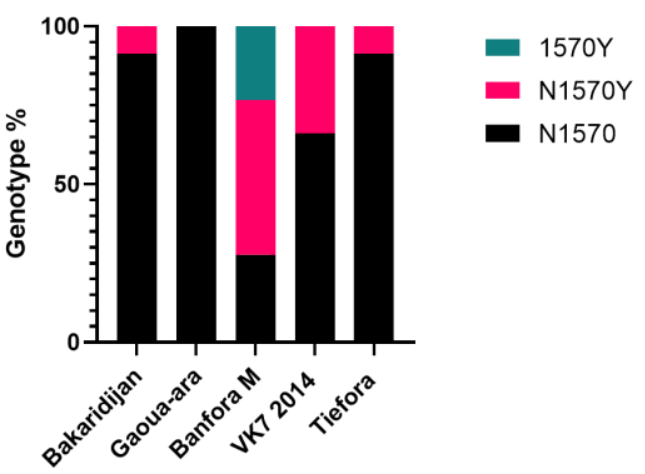

RDL A296S genotype frequencies

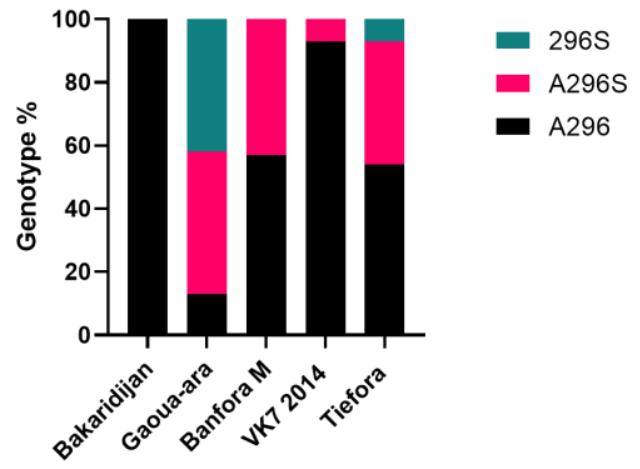

GSTE2 I114T genotype frequencies

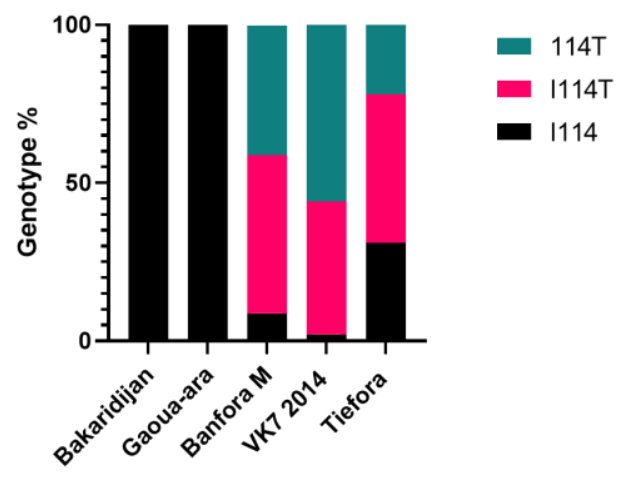

Figure 6. Frequency of point mutations associated with resistance. Data reported from samples genotyped in 2019. 995L, 1575N, 119G, 269A and 114I indicate the wildtype genotype (black bars); 995F, 995S, 1570Y, 119S, 296S and 114T indicate resistant genotype (green or purple bars). Heterozygote genotypes are shown with pink bars.

\subsection{Similarities between Strains}

The total number of genes differentially expressed across all the resistant compared to susceptible strains is shown in Supplementary Table S3. A total of 81 transcripts were up regulated in resistant versus susceptible strains with 73 down regulated. The upregulated transcripts show no enrichment but two P450s known to bind and/or metabolise pyrethroids (CYP6P3 and CYP6Z2) are amongst the most highly upregulated genes and two glucoronosyl transfearses (UGT302H2 and UGT306A2) are also elevated in all strains. 
Down regulated transcripts are strongly enriched for RNA processing $\left(p=1.25 \times 10^{-4}\right)$ and do not contain genes previously associated with pyrethroid resistance.

GO term enrichment was explored for each individual resistant population. Whilst no GO terms were enriched across all five resistant populations, a number of similarities were seen across the four resistant An. gambiae and An. coluzzii colonies (Supplementary Figure S3). GO terms significant in up-regulated genes across each population include oxidoreductase activity, typically seen in resistant colonies [34,35] and related to cytochrome p450 activity, and terms related to neuronal signalling, potentially indicating changes in signalling and neurotransmitter activity are associated with resistance to these neurotoxic insecticides. Additionally, terms related to ATPase activity and GPCR signalling, both previously linked to insecticide resistance [36,37] are seen. There are similarities in $\mathrm{GO}$ enrichments in the down-regulated subset of genes, with terms related to transcription factor activity, translational regulation, regulation of dephosphorylation and phosphatase complexes, all repressed (Supplementary Figure S4).

\subsection{Differences between Strains}

The RNAseq data was then interrogated to identify both pathways and a priori candidate genes enriched in the up or down regulated genes in each resistant strain with An. gambiae and An. coluzzii compared to two susceptible controls. Analysis at the individual gene level revealed key differences between the strains. For example, 23 P450s are differentially expressed in one or more strains; as mentioned above, CYP6P3 and CYP6Z2 are up-regulated in all resistant strains but other known pyrethroid metabolisers including CYP6M2, CYP6P2, P4 and P5 and CYP9J5 and 9K1 [38,39] are also up-regulated in two or more strains (Figure 7). This analysis also identifies a number of additional P450s that are highly up-regulated in multiple strains but have not yet been functionally characterised (e.g., CYP4H genes) which merit further study.
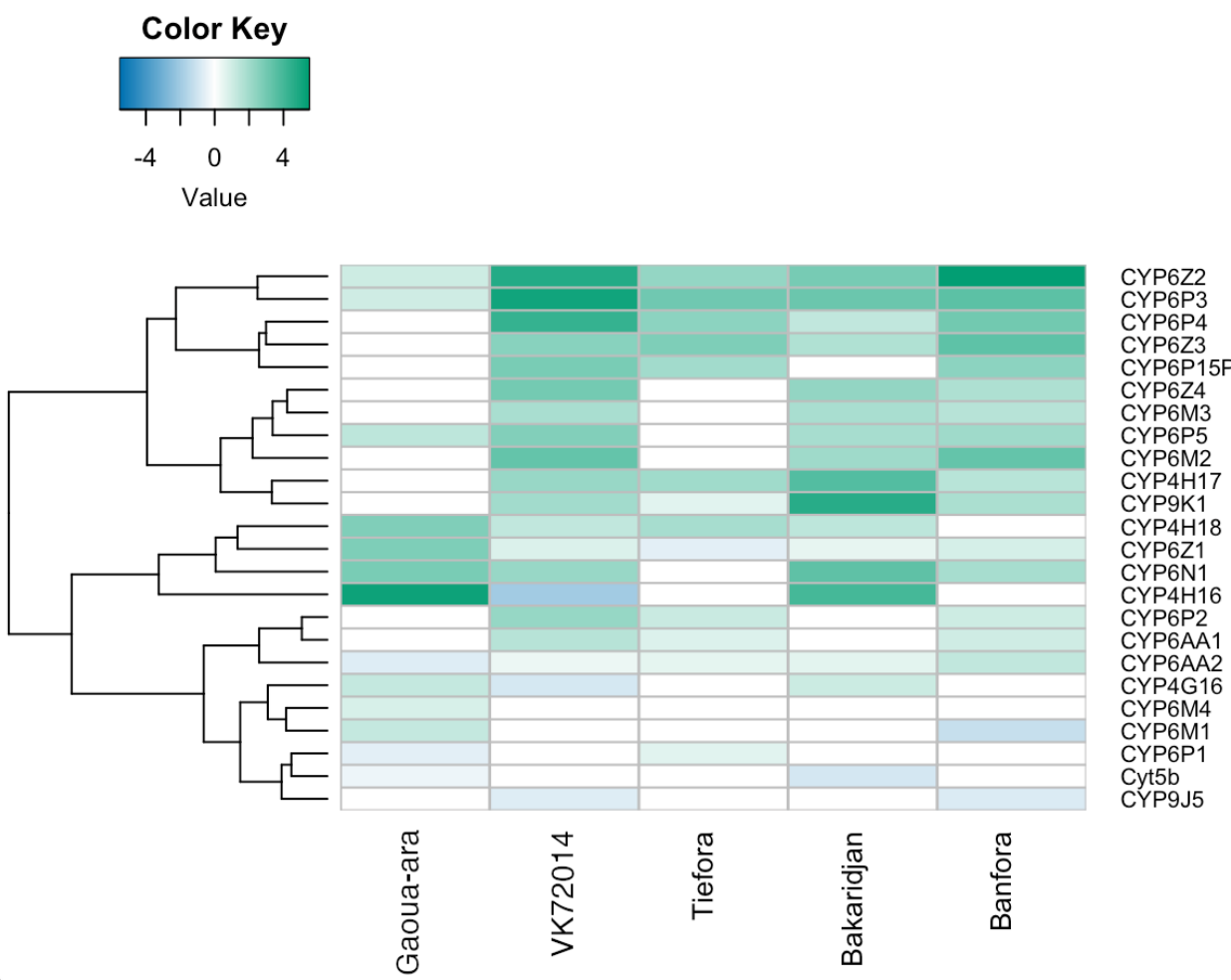

CYP9J5

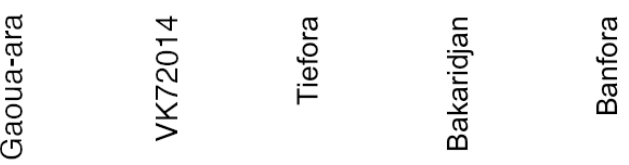

Figure 7. Heatmap showing cytochrome P450 genes that are significantly differentially expressed between the pyrethroid resistant and susceptible strains.

Recently, a number of genes with putative roles in sequestering pyrethroids were found to be over expressed in pyrethroid resistant populations from West Africa [40]. 
RNAseq data from the An. gambiae complex in Burkina Faso is supportive of a putative role of hexamerins in pyrethroid resistance in An. arabiensis and the VK7 strain of $A n$. coluzzii (as shown previously [37]) (Figure 8). Suppression of the hexamerin AGAP001659 (highly upregulated in Gaoua-ara in this study) was previously associated with a reduction in pyrethroid resistance [37]. In addition, several alpha- cyrstallins were up-regulated in one or more of the pyrethroid resistance populations, with this gene family particularly enriched in the Banfora strain of An. coluzzii in agreement with earlier qPCR data [40]. Suppression of the alpha-cyrstallin AGAP007159, which is upregulated in multiple Burkina populations, has also been shown to result in a reduction in the resistance phenotype in VK7 2014.

\section{Color Key}

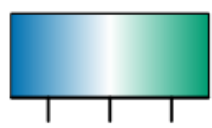

\section{$\begin{array}{lll}-5 & 0 & 5\end{array}$}

\section{Value}

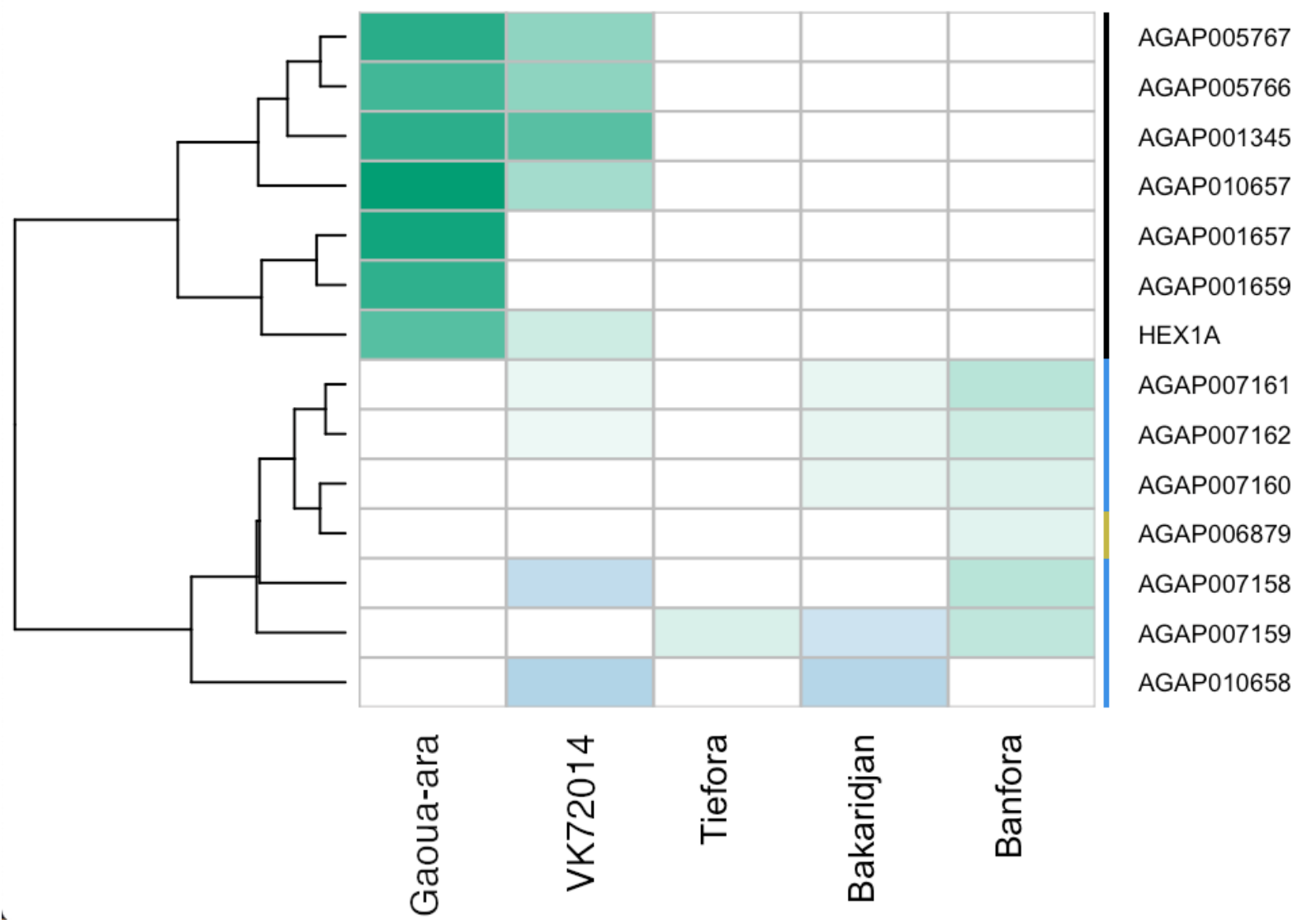

Figure 8. Heatmap showing differential expression of genes in families putatively associated with insecticide sequestration between the pyrethroid resistant and susceptible strains.

Finally, we looked at expression of genes recently implicated in the cuticular hydrocarbon (CHC) synthetic pathway. This gene list was derived from transcripts encoding the six gene families (propionyl co A synthases, fatty acid synthases, elongases, desaturases, reductases and $\mathrm{P} 450$ decarbonylases) that are enriched in the sub epidermal oenocyte cells responsible for $\mathrm{CHC}$ production [41]. Several genes in this pathway were up-regulated in the Banfora, Bakaridjan and Gaoua-ara strains but, surprisingly, down-regulated in two of 
the strains, Tiefora and VK7 2014 (Supplementary Figure S5). To date only two genes in this putative pathway have been functionally validated, CYP4G16 [42] and the fatty acid synthase FAS1899 [41]; both of these genes are upregulated in the pyrethroid resistant An. arabiensis strain (fold changes of 5.2 and 2- fold respectively) suggesting that cuticular resistance may be a particularly important resistance phenotype in this population.

\subsection{Evaluation of a Multiplex Gene Expression Assay for Metabolic Resistance}

RNAseq analysis provided a list of putative genes and pathways potentially contributing to the pyrethroid resistance phenotype in the different strains. However, simpler robust assays of gene expression are needed to further investigate the association between gene expression and resistance phenotype. To this end, the Taqman multiplex assay [32] was used to quantify relative expression of a subset of 8 insecticide detoxification genes in each of the resistant strains compared to their susceptible counterparts (to facilitate correlations with RNAseq data, expression levels from the An. gambiae and An. coluzzii resistant strains were compared to the average expression of the equivalent transcripts in the An. gambiae and $A n$. coluzzii susceptible strains). The data generated in this study agreed well with previous Taqman multiplex P450 expression data for VK7, with the exception of CYP9K1 (where significant up-regulation was not detected in earlier generations). P450 levels in Banfora appear more variable between generations, consistent with recent findings that the resistance phenotype is less stable in this population than in other laboratory colonies [28]. Within the current study, there is generally good agreement between the qPCR (Supplementary Figure S6 and Supplementary Table S4) and RNAseq data, with the exception of CYP6P3 and CYP6Z1 (Table 2).

Table 2. Summary of correlation between results of detoxification multiplex qPCR and RNAseq data.

\begin{tabular}{|c|c|c|c|c|c|}
\hline & \multicolumn{3}{|c|}{ An. coluzzii } & \multirow{2}{*}{$\begin{array}{c}\text { An. gambaie } \\
\text { Bakaridjan }\end{array}$} & \multirow{2}{*}{$\begin{array}{c}\text { An. arabiensis } \\
\text { Gaoua-ara }\end{array}$} \\
\hline & VK72014 & Banfora & Tiefora & & \\
\hline \multicolumn{6}{|l|}{ CYP4G16 } \\
\hline \multicolumn{6}{|l|}{ CYP6M2 } \\
\hline \multicolumn{6}{|l|}{ CYP6P1 } \\
\hline \multicolumn{6}{|l|}{ CYP6P3 } \\
\hline \multicolumn{6}{|l|}{ CYP6P4 } \\
\hline \multicolumn{6}{|l|}{ CYP6Z1 } \\
\hline \multicolumn{6}{|l|}{ CYP9K1 } \\
\hline \multicolumn{6}{|l|}{ GSTE2 } \\
\hline \multicolumn{6}{|c|}{ Genes up-regulated in both qPCR and RNAseq data set } \\
\hline \multicolumn{6}{|c|}{ Genes up-regulated in qPCR data set only } \\
\hline \multicolumn{6}{|c|}{ Genes up-regulated in RNAseq data set only } \\
\hline
\end{tabular}

\section{Discussion}

This study provides a detailed description of the extent and causes of pyrethroid resistance in three new colonies of An. gambiae s.l. from Burkina Faso and provides further information on the genetic basis of pyrethroid resistance in two colonies originating from the same region and described previously [9].

The high levels of pyrethroid resistance present in all five resistant strains, from three different species, reinforces the view that Burkina Faso is a hotspot of resistance [3,43-45]. All colonies were maintained under deltamethrin selection and data from WHO intensity assays show little difference in resistance levels between the strains. Although technically the $A n$. arabiensis colony is defined as moderately resistant whereas the four An. coluzzii and $A n$. gambiae strains meet the definition of high resistance, when time of exposure, rather than concentration of insecticide, was the variable, the An. gambiae s.s strain was the least resistant of the strains. Bioassays conducted in Burkina Faso in 2010 found that both $A n$. gambiae and An. coluzzii were significantly more likely to survive permethrin exposure than $A n$. arabiensis [46]; these species differences now seem to have been largely eroded, at least in the Burkina Faso populations assayed in this study. Several of the 
strains also showed resistance to other insecticide classes including carbamates and the cyclodiene, dieldrin. These insecticides are not used for mosquito control in this region and hence the observed resistance may be indicative of agricultural exposure selecting for resistance [3] (or alternatively may be explained by cross resistance between insecticide classes, see below). Insecticides from additional classes including the neonicotinoids and pyrrole, are now being incorporated into vector control products such as indoor residual sprays and ITNs and work is ongoing to assess the susceptibility of these laboratory colonies to these active ingredients. Encouragingly, all strains appear susceptible to the pyrrole chlorfenapyr, used in the ITN IG ${ }^{\circledR}$ (BASF, Germany) that is being deployed in pilot schemes in Burkina Faso [47].

Pre-exposure to the synergist $\mathrm{PBO}$, did increase permethrin induced mortality but could not fully restore susceptibility in any strain. Simultaneous exposure to PBO and pyrethroids typically resulted in higher mortalities than observed after sequential exposure, perhaps indicating that PBO acts as an adjuvant, as well as an inhibitor of P450s, as has been proposed previously [48] but mortality rates were still well below 100\% mortality. However, when mosquitoes from all five strains were exposed to a formulated product containing PBO (the roof of a Permanent 3.0 ITN) 100\% mortality was observed after just a 3 min exposure. This highlights the challenges of interpreting results from different bioassays and extrapolating to field effectiveness. High mortalities after exposure to ITNs containing PBO has been observed previously in cone bioassays on An. coluzzii from this region and experimental hut studies conducted the same year (2014) showed that PBO ITNs caused higher mosquito mortalities than standard pyrethroid only ITNs [49]. However, rising levels of pyrethroid resistance in the region, appear to be undermining the effectiveness of PBO nets (WMG, N'FS, unpublished data).

As expected, mutations in the VGSC gene, the target site of pyrethroids, were found in all strains, but there was a surprising variation in the frequency of the 'typical' $\mathrm{kdr}$ haplotypes, 995F and 995S. The 995S allele was only found in An. arabiensis and was found in approximately equal frequency to the $995 \mathrm{~F}$ allele, with the most prevalent genotype being 995F/995S heterozygotes. Similar heterozygotes have been detected in Cameroon and Gabon, with some evidence of a fitness advantage [13]. The $995 \mathrm{~S}$ allele was first reported in An. arabiensis in Burkina Faso in 2008 [46] and the reasons it remains confined to this member of the complex are unknown. The An. gambiae Bakaridjan strain and An. coluzzii VK7 2014 are both fixed for the 995F allele but this SNP was found at very low frequencies in the other two resistant An. coluzzii strains. Subsequent further investigations have detected an alternative VGSC haplotype in pyrethroid resistant An. coluzzii from Burkina Faso, consisting of a double mutation at codons 402 and 1527 [14] and have shown that the Banfora $\mathrm{M}$ and Tiefora laboratory colonies contain high frequencies of this 402L:1527T haplotype, which is mutually exclusive with the 995F haplotype. The functional significance of the two alternative VGSC resistance haplotypes is the subject of ongoing investigations, comparing the resistance phenotype and fitness costs, and genotyping resistant mosquitoes from neighbouring regions, to try and establish why there is an apparent evolutionary shift away from $995 \mathrm{~F}$ to alternative amino acid substitutions in these An coluzzii populations. In the context of the current study, it is interesting that the 402L:1527T haplotype is only present in one species of the colonies of An. gambiae s.l. that were established from the same larval collections in the same breeding sites (Bakaridjan and Banfora $\mathrm{M}$ ). Introgression of $\mathrm{kdr}$ alleles between members of the An. gambiae complex has occurred on multiple occasions [50] and longitudinal monitoring of the frequency of these alternative haplotypes in the Cascades region of Burkina Faso may provide an opportunity to monitor any further genetic exchange in this genomic region.

The three new strains described in the current study all contain some level of carbamate resistance, but the target site allele Ace- 1 is absent in two of the strains and found at very low frequencies in the third (Tiefora). The persistence of carbamate resistance in these strains for multiple generations in the insectary, in the absence of carbamate selection, together with the absence of target site resistance, point to possible cross resistance between 
pyrethroids and carbamates. CYP6P3, which is elevated in all of the resistant strains, has been shown to metabolise a wide range of insecticides from different classes, including the carbamate bendiocarb $[39,51]$.

The 'resistance to dieldrin' Rdl allele 296S is found at frequencies exceeding $20 \%$ in the three newly described strains and its frequency broadly correlates with the prevalence of dieldrin resistance in these strains, with Gaoua-ara (Rdl frequency 0.65) the most resistant to dieldrin. The point mutation GSTE2-114T, which results in an enhanced version of the detox gene Gste2 known to metabolise DDT [30], was found in the three An. coluzzii strains at relatively high frequencies (above 0.46 in all cases). All of these strains are highly resistant to DDT; however, the contribution of the GSTE2-114T allele to DDT resistance is difficult to assess in these strains given the presence of target site resistance and the finding that expression levels of GSTE2 are elevated in these resistant strains

RNAseq was used to identify additional resistance mechanisms potentially contributing to the intense pyrethroid resistance phenotype in these strains. The up-regulation of several P450s, together with the partial synergism conferred by PBO, confirmed the importance of this mechanism with many of the known pyrethroid metabolisers up-regulated in multiple strains and the three subfamilies $(6 \mathrm{P}, 6 \mathrm{M}$ and $6 \mathrm{Z})$ most widely associated with pyrethroid resistance amongst [39] the most up-regulated, particularly in the An. coluzzii strains. Interestingly, in the An. arabiensis and An. gambiae populations, some of the strongest candidates, based on expression levels alone, are found in other subfamilies of $\mathrm{P} 450$ s, notably the CYP4H family for An. arabiensis which has been implicated in pyrethroid resistance in previous microarray studies $[23,52,53]$ but has not, to our knowledge, been functionally characterised.

In addition, genes thought to play a part in the synthesis and deposition of hydrocarbons on the mosquito cuticle [41] were up-regulated in some strains. Elevated levels of cuticular hydrocarbons have been associated with pyrethroid resistance in An. coluzzii mosquitoes from Valle du Kou [10,54] in Burkina Faso and evidence of an association between epicuticle thickness and insecticide resistance has been reported in several additional Anopheles populations $[11,55]$. As this resistance mechanism may confer cross resistance to a wide range of contact insecticides, it is important that insecticide screening pipelines incorporate strains with thickened cuticles. However, our own observations indicate that this mechanism may be less stable in laboratory colonies than other resistance mechanisms, perhaps indicative of a high fitness cost which is balanced by other phenotypic advantages, such as ability to withstand desiccation [56], or mating advantage [10].

Further putative resistance mechanisms are indicated by examination of the RNAseq but have not been functionally validated. For example, two odorant binding proteins (AGAP000278 and AGAP012867) are up-regulated in all of the pyrethroid resistant populations from Burkina Faso. The chemosensory protein SAP2, expressed in mosquito legs and antennae, has already been shown to play a key role in pyrethroid resistance in An. gambiae s.l from Burkina Faso but [12], whilst OBPs have been associated with resistance in other studies [57,58], a direct role for this family in pyrethroid resistance remains to be demonstrated. Other gene families putatively involved in insecticide binding (and maybe sequestration) were elevated in multiple Burkina populations, most notably the hexamerins, found in the mosquito haemeolymph where they act as storage and transport proteins, which are highly enriched in the An. arabiensis resistant strain. The absence of DNA markers for these putative resistance mechanisms makes it difficult to evaluate their individual contributions to the phenotype but temporary loss of function via RNAi has been successfully used in the past to demonstrate a link between individual genes within putative insecticide binding protein families and resistance [40]. In vitro studies on recombinant proteins are also needed, both to confirm their role in pyrethroid binding, but importantly also to assess the ability to bind other insecticide classes. 


\section{Conclusions}

This study demonstrates that different species within a species complex, collected from the same geographical area (including two originating from the same larval collections) and hence presumably under similar selection pressures, can evolve multiple, different resistance mechanisms. This may be indicative of the exceptionally strong selection pressure exerted on Anopheles mosquitoes in this major agricultural region in Burkina Faso but it presents a major challenge for existing and new insecticide based control tools. As the strains have been maintained under selection pressure in the laboratory, the fitness costs of alternative mechanisms, and hence their stability under natural settings, are unknown but nevertheless the strains represent a valuable biological resource for the screening of new insecticides for potential resistance liabilities. From an evolutionary perspective, genomic sequencing of these strains, coupled with further sampling of sympatric members of the species complex in the region, provides an opportunity to investigate the role of introgression versus de novo mutation, in the evolution of resistance, and in assessing the response to the introduction of ITNs with new classes of insecticides.

Supplementary Materials: The following supporting information can be downloaded at: https: / / www.mdpi.com/article/10.3390/insects13030247/s1, Supplementary Table S1. Complete mortality data for standard PBO bioassays plus PBO: perm synergism ratios for five resistant strains. Mean mortality rates (\%) across three reps $24 \mathrm{~h}$ after exposure are given, minimum sample size 75 . Supplementary Table S2. Complete mortality data for simultaneous and sequential exposures of PBO with either permethrin and deltamethrin plus PBO synergism rations for five resistant strains. Mean mortality rates (\%) across three reps $24 \mathrm{~h}$ after exposure are given, minimum sample size 75 . Supplementary Table S3. The total number of genes differentially expressed across resistant compared to susceptible strains. Supplementary Table S4. qPCR data showing expression levels of the panel of detoxification genes in the five resistant strains. Mean fold changes from 3 biological replicates and 3 technical replicates, relative to susceptible strain(s), SD = standard deviation. Data have been normalised against expression in the susceptible strain as described in the methods. Supplementary Figure S1: PBO synergism results for three resistant anopheline strains with simultaneous and sequential exposures to PBO and permethrin (Perm) or deltamethrin (Delta). Mortality rates \% (24) hours after exposure. Minimal sample size $n=80$. Error bars represent $95 \%$ binomial confidence intervals. Statistical differences between insecticide only and $\mathrm{PBO}+$ insecticide are indicated as ${ }^{*} p<0.05$, or ns- not significant. Supplementary Figure S2: RNA Correlation matrix for five resistant strains and three susceptible strains. Red represents a strong correlation and blue represents a disassociation. VK7 = VK7 2014, Bak = Bakaridjan, T = Tiefora, $\mathrm{K}=$ Kisumu, B = Banfora M, NG = N'Gousso, $\mathrm{M}=$ Moz, G= Gaoua-ara. Supplementary Figure S3: GO terms enrichment up regulation for five resistant strains. Supplementary Figure S4: GO terms enrichment down regulation for five resistant strains. Supplementary Figure S5: Expression of genes in the cuticular hydrocarbon production pathway in five resistant strains. Blue represents genes down regulated and green represents genes upregulated. Reduct $=$ reductase, Elong = elongase, Desat $=$ desaturase, FAS = fatty acid synthase. Supplementary Figure S6: qPCR P450 expression in five resistant strains. Error bars represent standard deviations, statistically significant differences in expression level relative to susceptible strains are indicated as ${ }^{*} p<0.05,{ }^{* *} p<0.01,{ }^{* * *} p \leq 0.001$ ANOVA test followed by Dunnett's or Dunn test.

Author Contributions: Conceptualization, H.R.; Data curation, V.A.I.; Formal analysis, J.W. and V.A.I.; Funding acquisition, V.A.I. and H.R.; Investigation, J.W., V.A.I. and M.M.; Resources, K.H.T., A.S.H., J.C.M., R.K.D., W.M.G. and N.S.; Supervision, R.K.D., W.M.G., N.S. and H.R.; Visualization, J.W. and V.A.I.; Writing-original draft, J.W., V.A.I. and H.R.; Writing—review and editing, K.H.T., W.M.G. and N.S. All authors have read and agreed to the published version of the manuscript. 
Funding: This research was funded by a PhD studentship to J.W from IVCC, an MRC Skills Development Fellowship to V.I (MR/R024839/1). We also acknowledge support from Wellcome Trust, Grant/Award Number: 200222/Z/15/Z and the Medical Research Council of the UK (grant number MR/P027873/1) through the Global Challenges Research Fund.

Institutional Review Board Statement: Not applicable.

Data Availability Statement: All RNAseq data is freely available on SRA under accessions PRJNA780362 and PRJNA750256. Custom code for enrichment analysis is available on GitHub at https:/ / github.com/VictoriaIngham/BurkinsStrains.

Acknowledgments: The authors would like to thank the teams at Centre National de Recherche et de Formation sur le Paludisme (CNRFP) and Institut de Recherche en Sciences de la Santé (IRSS) for assistance with field collections of mosquitoes; the members of Liverpool Insect Testing Establishment (LITE) team, and the member of the Vector Biology Insectary team at the Liverpool School of Tropical Medicine (LSTM) for assistance with rearing mosquitoes and conducting the routine profiling of colonies.

Conflicts of Interest: The authors declare no conflict of interests.

\section{References}

1. Oxborough, R.M. Trends in US President's Malaria Initiative-funded indoor residual spray coverage and insecticide choice in sub-Saharan Africa (2008-2015): Urgent need for affordable, long-lasting insecticides. Malar. J. 2016, 15, 146. [CrossRef]

2. Nkya, T.E.; Akhouayri, I.; Kisinza, W.; David, J.P. Impact of environment on mosquito response to pyrethroid insecticides: Facts, evidences and prospects. Insect Biochem. Mol. Biol. 2013, 43, 407-416. [CrossRef] [PubMed]

3. Hien, A.S.; Soma, D.D.; Hema, O.; Bayili, B.; Namountougou, M.; Gnankiné, O.; Baldet, T.; Diabaté, A.; Dabiré, K.R. Evidence that agricultural use of pesticides selects pyrethroid resistance within Anopheles gambiae s.l. populations from cotton growing areas in Burkina Faso, West Africa. PLoS ONE 2017, 12, e0173098. [CrossRef] [PubMed]

4. Brown, A.W. Insecticide resistance in mosquitoes: A pragmatic review. J. Am. Mosq. Control Assoc. 1986, 2, 123-140. [PubMed]

5. Ranson, H.; Lissenden, N. Insecticide Resistance in African Anopheles Mosquitoes: A Worsening Situation that Needs Urgent Action to Maintain Malaria Control. Trends Parasitol. 2016, 32, 187-196. [CrossRef]

6. Lees, R.; Praulins, G.; Davies, R.; Brown, F.; Parsons, G.; White, A.; Ranson, H.; Small, G.; Malone, D. A testing cascade to identify repurposed insecticides for next-generation vector control tools: Screening a panel of chemistries with novel modes of action against a malaria vector. Gates Open Res. 2019, 3, 1464. [CrossRef] [PubMed]

7. Turner, J.A.; Ruscoe, C.N.; Perrior, T.R. Discovery to Development: Insecticides for Malaria Vector Control. Chimia 2016, 70, 684-693. [CrossRef]

8. Lees, R.S.; Ismail, H.M.; Logan, R.A.E.; Malone, D.; Davies, R.; Anthousi, A.; Adolfi, A.; Lycett, G.J.; Paine, M.J.I. New insecticide screening platforms indicate that Mitochondrial Complex I inhibitors are susceptible to cross-resistance by mosquito P450s that metabolise pyrethroids. Sci. Rep. 2020, 10, 16232. [CrossRef]

9. Williams, J.; Flood, L.; Praulins, G.; Ingham, V.A.; Morgan, J.; Lees, R.S.; Ranson, H. Characterisation of Anopheles strains used for laboratory screening of new vector control products. Parasites Vectors 2019, 12, 522. [CrossRef]

10. Adams, K.L.; Sawadogo, S.P.; Nignan, C.; Niang, A.; Paton, D.G.; Robert Shaw, W.; South, A.; Wang, J.; Itoe, M.A.; Werling, K.; et al Cuticular hydrocarbons are associated with mating success and insecticide resistance in malaria vectors. Commun. Biol. 2021, 4, 911. [CrossRef]

11. Balabanidou, V.; Kampouraki, A.; MacLean, M.; Blomquist, G.J.; Tittiger, C.; Juárez, M.P.; Mijailovsky, S.J.; Chalepakis, G.; Anthousi, A.; Lynd, A.; et al. Cytochrome P450 associated with insecticide resistance catalyzes cuticular hydrocarbon production in Anopheles gambiae. Proc. Natl. Acad. Sci. USA 2016, 113, 9268-9273. [CrossRef] [PubMed]

12. Ingham, V.A.; Anthousi, A.; Douris, V.; Harding, N.J.; Lycett, G.; Morris, M.; Vontas, J.; Ranson, H. A sensory appendage protein protects malaria vectors from pyrethroids. Nature 2020, 577, 376-380. [CrossRef]

13. Clarkson, C.S.; Miles, A.; Harding, N.J.; O’Reilly, A.O.; Weetman, D.; Kwiatkowski, D.; Donnelly, M.J. The genetic architecture of target-site resistance to pyrethroid insecticides in the African malaria vectors Anopheles gambiae and Anopheles coluzzii. Mol. Ecol. 2021, 30, 5303-5317. [CrossRef] [PubMed]

14. Williams, J.; Cowlishaw, R.; Sanou, A.; Ranson, H.; Grigoraki, L. In vivo functional validation of the V402L voltage gated sodium channel mutation in the malaria vector An. gambiae. Pest Manag. Sci. 2022, 78, 1155-1163. [CrossRef] [PubMed]

15. Namountougou, M.; Simard, F.; Baldet, T.; Diabaté, A.; Ouédraogo, J.B.; Martin, T.; Dabiré, R.K. Multiple Insecticide Resistance in Anopheles gambiae s.l. Populations from Burkina Faso, West Africa. PLoS ONE 2012, 7, e48412. [CrossRef]

16. Grau-Bové, X.; Tomlinson, S.; O’Reilly, A.O.; Harding, N.J.; Miles, A.; Kwiatkowski, D.; Donnelly, M.J.; Weetman, D.; The Anopheles gambiae 1000 Genomes Consortium. Evolution of the Insecticide Target Rdl in African Anopheles Is Driven by Interspecific and Interkaryotypic Introgression. Mol. Biol. Evol. 2020, 37, 2900-2917. [CrossRef] 
17. Norris, L.C.; Main, B.J.; Lee, Y.; Collier, T.C.; Fofana, A.; Cornel, A.J.; Lanzaro, G.C. Adaptive introgression in an African malaria mosquito coincident with the increased usage of insecticide-treated bed nets. Proc. Natl. Acad. Sci. USA 2015, 112, 815-820. [CrossRef]

18. Namountougou, M.; Soma, D.D.; Kientega, M.; Balboné, M.; Kaboré, D.P.A.; Drabo, S.F.; Coulibaly, A.Y.; Fournet, F.; Baldet, T.; Diabaté, A.; et al. Insecticide resistance mechanisms in Anopheles gambiae complex populations from Burkina Faso, West Africa. Acta Trop. 2019, 197, 105054. [CrossRef]

19. Sanou, A.; Nelli, L.; Guelbéogo, W.M.; Cissé, F.; Tapsoba, M.; Ouédraogo, P.; Sagnon, N.; Ranson, H.; Matthiopoulos, J.; Ferguson H.M. Insecticide resistance and behavioural adaptation as a response to long-lasting insecticidal net deployment in malaria vectors in the Cascades region of Burkina Faso. Sci. Rep. 2021, 11, 17569. [CrossRef]

20. MR4. Anopheles Laboratory Biology and Culture. Methods in Anopheles Research; MR4, Atlanta Centers for Disease Control and Prevention: Manassas, VA, USA, 2014; pp. 1-8.

21. Fanello, C.; Santolamazza, F.; della Torre, A. Simultaneous identification of species and molecular forms of the Anopheles gambiae complex by PCR-RFLP. Med. Vet. Entomol. 2002, 16, 461-464. [CrossRef]

22. Harris, C.; Lambrechts, L.; Rousset, F.; Abate, L.; Nsango, S.E.; Fontenille, D.; Morlais, I.; Cohuet, A. Polymorphisms in Anopheles gambiae immune genes associated with natural resistance to Plasmodium falciparum. PLoS Pathog. 2010, 6, e1001112. [CrossRef] [PubMed]

23. Witzig, C.; Parry, M.; Morgan, J.C.; Irving, H.; Steven, A.; Cuamba, N.; Kerah-Hinzoumbé, C.; Ranson, H.; Wondji, C.S. Genetic mapping identifies a major locus spanning P450 clusters associated with pyrethroid resistance in kdr-free Anopheles arabiensis from Chad. Heredity 2013, 110, 389-397. [CrossRef]

24. World Health Organization. Test Procedures for Insecticide Resistance Monitoring in Malaria Vector Mosquitoes; World Health Organization: Geneva, Switzerland, 2016.

25. World Health Organization. Guidelines for Laboratory and Field-Testing of Long-Lasting Insecticidal Nets; World Health Organization: Geneva, Switzerland, 2013.

26. Bass, C.; Nikou, D.; Donnelly, M.J.; Williamson, M.S.; Ranson, H.; Ball, A.; Vontas, J.; Field, L.M. Detection of knockdown resistance (kdr) mutations in Anopheles gambiae: A comparison of two new high-throughput assays with existing methods. Malar. J. 2007, 6, 111. [CrossRef] [PubMed]

27. Jones, C.M.; Liyanapathirana, M.; Agossa, F.R.; Weetman, D.; Ranson, H.; Donnelly, M.J.; Wilding, C.S. Footprints of positive selection associated with a mutation (N1575Y) in the voltage-gated sodium channel of Anopheles gambiae. Proc. Natl. Acad. Sci. USA 2012, 109, 6614-6619. [CrossRef] [PubMed]

28. Dabire, R.K.; Namountougou, M.; Diabate, A.; Soma, D.D.; Bado, J.; Toe, H.K.; Bass, C.; Combary, P. Distribution and frequency of kdr mutations within Anopheles gambiae s.l. populations and first report of the ace.1 G119S mutation in Anopheles arabiensis from Burkina Faso (West Africa). PLoS One 2014, 9, e101484. [CrossRef]

29. Bass, C.; Nikou, D.; Vontas, J.; Donnelly, M.J.; Williamson, M.S.; Field, L.M. The Vector Population Monitoring Tool (VPMT): High-Throughput DNA-Based Diagnostics for the Monitoring of Mosquito Vector Populations. Malar. Res. Treat. 2010, 2010, 190434. [CrossRef]

30. Mitchell, S.N.; Rigden, D.J.; Dowd, A.J.; Lu, F.; Wilding, C.S.; Weetman, D.; Dadzie, S.; Jenkins, A.M.; Regna, K.; Boko, P.; et al Metabolic and target-site mechanisms combine to confer strong DDT resistance in Anopheles gambiae. PLoS One 2014, 9, e92662. [CrossRef]

31. Ingham, V.A.; Tennessen, J.A.; Lucas, E.R.; Elg, S.; Yates, H.C.; Carson, J.; Guelbeogo, W.M.; Sagnon, N.; Hughes, G.L.; Heinz, E.; et al. Integration of whole genome sequencing and transcriptomics reveals a complex picture of the reestablishment of insecticide resistance in the major malaria vector Anopheles coluzzii. PLoS Genet. 2021, 17, e1009970. [CrossRef]

32. Mavridis, K.; Wipf, N.; Medves, S.; Erquiaga, I.; Müller, P.; Vontas, J. Rapid multiplex gene expression assays for monitoring metabolic resistance in the major malaria vector Anopheles gambiae. Parasite Vectors 2019, 12, 9. [CrossRef]

33. Schmittgen, T.D.; Livak, K.J. Analyzing real-time PCR data by the comparative C(T) method. Nat Protoc 2008, 3, 1101-1108. [CrossRef]

34. Wondji, C.S.; Irving, H.; Morgan, J.; Lobo, N.F.; Collins, F.H.; Hunt, R.H.; Coetzee, M.; Hemingway, J.; Ranson, H. Two duplicated P450 genes are associated with pyrethroid resistance in Anopheles funestus, a major malaria vector. Genome Res. 2009, 19, 452-459. [CrossRef]

35. Ingham, V.A.; Jones, C.M.; Pignatelli, P.; Balabanidou, V.; Vontas, J.; Wagstaff, S.C.; Moore, J.D.; Ranson, H. Dissecting the organ specificity of insecticide resistance candidate genes in Anopheles gambiae: Known and novel candidate genes. BMC Genom. 2014, 15, 1018. [CrossRef] [PubMed]

36. Kefi, M.; Charamis, J.; Balabanidou, V.; Ioannidis, P.; Ranson, H.; Ingham, V.A.; Vontas, J. Transcriptomic analysis of resistance and short-term induction response to pyrethroids, in Anopheles coluzzii legs. BMC Genom. 2021, 22, 891. [CrossRef] [PubMed]

37. Pignatelli, P.; Ingham, V.A.; Balabanidou, V.; Vontas, J.; Lycett, G.; Ranson, H. The Anopheles gambiae ATP-binding cassette transporter family: Phylogenetic analysis and tissue localization provide clues on function and role in insecticide resistance. Insect Mol. Biol. 2018, 27, 110-122. [CrossRef]

38. Vontas, J.; Grigoraki, L.; Morgan, J.; Tsakireli, D.; Fuseini, G.; Segura, L.; Niemczura de Carvalho, J.; Nguema, R.; Weetman, D.; Slotman, M.A.; et al. Rapid selection of a pyrethroid metabolic enzyme CYP9K1 by operational malaria control activities. Proc. Natl. Acad. Sci. USA 2018, 115, 4619-4624. [CrossRef] [PubMed] 
39. Yunta, C.; Hemmings, K.; Stevenson, B.; Koekemoer, L.L.; Matambo, T.; Pignatelli, P.; Voice, M.; Nász, S.; Paine, M.J.I. Crossresistance profiles of malaria mosquito P450s associated with pyrethroid resistance against WHO insecticides. Pestic. Biochem. Physiol. 2019, 161, 61-67. [CrossRef] [PubMed]

40. Ingham, V.A.; Wagstaff, S.; Ranson, H. Transcriptomic meta-signatures identified in Anopheles gambiae populations reveal previously undetected insecticide resistance mechanisms. Nat. Commun. 2018, 9, 5282. [CrossRef]

41. Grigoraki, L.; Grau-Bové, X.; Carrington Yates, H.; Lycett, G.J.; Ranson, H. Isolation and transcriptomic analysis of Anopheles gambiae oenocytes enables the delineation of hydrocarbon biosynthesis. Elife 2020, 9. [CrossRef]

42. Lynd, A.; Balabanidou, V.; Grosman, R.; Maas, J.; Lian, L.-Y.; Vontas, J.; Lycett, G.J. Development of a functional genetic tool for Anopheles gambiae oenocyte characterisation: Application to cuticular hydrocarbon synthesis. bioRxiv 2019, 742619.

43. Hughes, A.; Lissenden, N.; Viana, M.; Toé, K.H.; Ranson, H. Anopheles gambiae populations from Burkina Faso show minimal delayed mortality after exposure to insecticide-treated nets. Parasites Vectors 2020, 13, 17. [CrossRef]

44. Toé, K.H.; Jones, C.M.; N’Fale, S.; Ismail, H.M.; Dabiré, R.K.; Ranson, H. Increased pyrethroid resistance in malaria vectors and decreased bed net effectiveness, Burkina Faso. Emerg. Infect. Dis. 2014, 20, 1691-1696. [CrossRef] [PubMed]

45. Toé, K.H.; N’Falé, S.; Dabiré, R.K.; Ranson, H.; Jones, C.M. The recent escalation in strength of pyrethroid resistance in Anopheles coluzzi in West Africa is linked to increased expression of multiple gene families. BMC Genom. 2015, 16, 146. [CrossRef] [PubMed]

46. Badolo, A.; Traore, A.; Jones, C.M.; Sanou, A.; Flood, L.; Guelbeogo, W.M.; Ranson, H.; Sagnon, N.F. Three years of insecticide resistance monitoring in Anopheles gambiae in Burkina Faso: Resistance on the rise? Malar. J. 2012, 11, 232. [CrossRef]

47. Gansané, A.; Candrinho, B.; Mbituyumuremyi, A.; Uhomoibhi, P.; Nfalé, S.; Mohammed, A.B.; Guelbeogo, W.M.; Sanou, A.; Kangoye, D.; Debe, S.; et al. Design and methods for a quasi-experimental pilot study to evaluate the impact of dual active ingredient insecticide-treated nets on malaria burden in five regions in sub-Saharan Africa. Malar. J. 2022, $21,19$. [CrossRef] [PubMed]

48. Glynne-Jones, D.E. Piperonyl Butoxide: The Insecticide Synergist. Academic Press: San Diego, California, USA, $1998 ;$ p. 323.

49. Toe, K.H.; Müller, P.; Badolo, A.; Traore, A.; Sagnon, N.; Dabiré, R.K.; Ranson, H. Do bednets including piperonyl butoxide offer additional protection against populations of Anopheles gambiae s.l. that are highly resistant to pyrethroids? An experimental hut evaluation in Burkina Fasov. Med. Vet. Entomol. 2018, 32, 407-416. [CrossRef]

50. Pinto, J.; Lynd, A.; Vicente, J.L.; Santolamazza, F.; Randle, N.P.; Gentile, G.; Moreno, M.; Simard, F.; Charlwood, J.D.; do Rosário, V.E.; et al. Multiple origins of knockdown resistance mutations in the Afrotropical mosquito vector Anopheles gambiae. PLoS ONE 2007, 2, e1243. [CrossRef] [PubMed]

51. Edi, C.V.; Djogbénou, L.; Jenkins, A.M.; Regna, K.; Muskavitch, M.A.; Poupardin, R.; Jones, C.M.; Essandoh, J.; Kétoh, G.K.; Paine, M.J.; et al. CYP6 P450 enzymes and ACE-1 duplication produce extreme and multiple insecticide resistance in the malaria mosquito Anopheles gambiae. PLoS Genet. 2014, 10, e1004236. [CrossRef]

52. Abdalla, H.; Wilding, C.S.; Nardini, L.; Pignatelli, P.; Koekemoer, L.L.; Ranson, H.; Coetzee, M. Insecticide resistance in Anopheles arabiensis in Sudan: Temporal trends and underlying mechanisms. Parasites Vectors 2014, 7, 213. [CrossRef]

53. Jones, C.M.; Toé, H.K.; Sanou, A.; Namountougou, M.; Hughes, A.; Diabaté, A.; Dabiré, R.; Simard, F.; Ranson, H. Additional selection for insecticide resistance in urban malaria vectors: DDT resistance in Anopheles arabiensis from Bobo-Dioulasso, Burkina Faso. PLoS ONE 2012, 7, e45995. [CrossRef]

54. Balabanidou, V.; Kefi, M.; Aivaliotis, M.; Koidou, V.; Girotti, J.R.; Mijailovsky, S.J.; Juárez, M.P.; Papadogiorgaki, E.; Chalepakis, G.; Kampouraki, A.; et al. Mosquitoes cloak their legs to resist insecticides. Proc. Biol. Sci. 2019, 286, 20191091. [CrossRef]

55. Yahouédo, G.A.; Chandre, F.; Rossignol, M.; Ginibre, C.; Balabanidou, V.; Mendez, N.G.A.; Pigeon, O.; Vontas, J.; Cornelie, S Contributions of cuticle permeability and enzyme detoxification to pyrethroid resistance in the major malaria vector Anopheles gambiae. Sci. Rep. 2017, 7, 11091. [CrossRef] [PubMed]

56. Reidenbach, K.R.; Cheng, C.; Liu, F.; Liu, C.; Besansky, N.J.; Syed, Z. Cuticular differences associated with aridity acclimation in African malaria vectors carrying alternative arrangements of inversion 2La. Parasites Vectors 2014, 7, 176. [CrossRef]

57. Liu, X.Q.; Jiang, H.B.; Liu, Y.; Fan, J.Y.; Ma, Y.J.; Yuan, C.Y.; Lou, B.H.; Wang, J.J. Odorant binding protein 2 reduces imidacloprid susceptibility of Diaphorina citri. Pestic. Biochem. Physiol. 2020, 168, 104642. [CrossRef] [PubMed]

58. Zhang, X.Q.; Yan, Q.; Li, L.L.; Xu, J.W.; Mang, D.; Wang, X.L.; Hoh, H.H.; Ye, J.; Ju, Q.; Ma, Y.; et al. Different binding properties of two general-odorant binding proteins in Athetis lepigone with sex pheromones, host plant volatiles and insecticides. Pestic. Biochem. Physiol. 2020, 164, 173-182. [CrossRef] [PubMed] 